\title{
MODIFIKASI PATI SUKUN (Artocarpus altilis) MENGGUNAKAN ANHIDRIDA ASAM ASETAT DAN APLIKASINYA PADA PEMBUATAN MIE
}

\section{[Modified Breadfruit (Artocarpus altilis) Starch Using Acetic Acid Anhydride and Its Application for Noodles Production]}

\author{
Nurhaeni ${ }^{1}$, Pratiwi Dwiasmukti ${ }^{1^{\star}}$, Prismawiryanti $^{1}$ \\ 1 Jurusan Kimia Fakultas MIPA, Universitas Tadulako \\ Jl. Soekarno Hatta Km.9, Kampus Bumi Tadulako Tondo Palu, Telp. 0451- 422611 \\ *)Coresponding author: dwiasmuktipratiwi@gmail.com (hp. +62853 4224 2820)
}

Diterima 28 Desember 2017, Disetujui 29 Januari 2018

\begin{abstract}
The research about the modified breadfruit (Artocarpus altilis) starch using acetic acid anhydride and its application for noodle production has been done to determine the best of acetic acid anhydride concentration, to yield high acetyl content and substitution degree. CRD (completely randomized design) was used in this research with 5 levels of acetic acid anhydride concentration $(0.05 \% ; 0.10 \%$; $0.15 \% ; 0.20 \%$ and $0.25 \%$ ). Each treatment was done in duplo. The results showed that the best acetic acid anhydride concentration was $0.25 \%$,with $5.75 \%$ acetyl content and 0.23 of substitution degree. The result of organoleptic test on taste and texture parameters, revealed that breadfruit starch acetate noodle was more preferable than native starch noodles.
\end{abstract}

Keywords: Breadfruit, breadfruit starch acetate, acetyl content, substitution degree.

\begin{abstract}
ABSTRAK
Penelitian tentang modifikasi pati sukun (Artocarpus altilis) menggunakan anhidrida asam asetat dan aplikasinya pada pembuatan mie telah dilakukan. Penelitian ini bertujuan untuk mengetahui konsentrasi anhidrida asam asetat terbaik dalam menghasilkan kadar asetil dan derajat substitusi tinggi. Penelitian ini menggunakan Rancangan Acak Lengkap (RAL) yaitu konsentrasi anhidrida asam asetat terdiri atas 5 taraf $(0,05 \% ; 0,10 \% ; 0,15 \% ; 0,20 \%$ dan $0,25 \%)$ dilakukan sebanyak 2 kali pengulangan untuk masing-masing taraf sehingga didapatkan 10 unit percobaan. Hasil penelitian menunjukan konsentrasi anhidrida asam asetat terbaik diperoleh pada 0,25\% dengan kadar asetil $5,75 \%$, dan derajat substitusi 0,23 . Hasil uji organoleptik pada parameter rasa dan tekstur, mie pati sukun asetat lebih disukai dibandingkan dengan mie pati alami.
\end{abstract}

Kata Kunci : Sukun, pati sukun asetat, kadar asetil,derajat substitusi. 


\section{LATAR BELAKANG}

Komoditas pangan di Indonesia memiliki ketesediaan yang melimpah khususnya sebagai bahan baku tepung. Salah satu komoditas pangan yang belum banyak termanfaatkan secara maksimal ke arah tersebut adalah tanaman sukun. Tanaman sukun tumbuh subur di Indonesia karena iklim yang sesuai dan menghasilkan buah yang sangat melimpah. Buah sukun (Artocarpus altilis) menjadi alternatif sebagai sumber karbohidrat dan dimanfaatkan pada substitusi tepung terigu (Triyani dkk, 2013).

Daya guna dan nilai ekonomi sukun dapat ditingkatkan melalui upaya pemanfaatan kandungan patinya untuk membuat berbagai jenis produk olahannya, seperti kripik dan mie instan. Pati yang menjadi komponen utama dalam buah sukun memiliki beberapa kelemahan sebagaimana pati dari sumber pangan lainnya, diantaranya mudah mengembang, viskositas rendah pada saat dipanaskan dan diaduk secara mekanik (Loos dkk, 1981 dalam Medikasari dkk, 2009). Untuk mengatasi hal tersebut maka dapat ditingkatkan melalui modifikasi pati. (Medikasari dkk, 2009).

Modifikasi pati dapat dilakukan melalui perlakuan terkendali secara fisik ataupun kimia sehingga akan mengubah sifat pati. Pati alami dapat dibuat menjadi pati temodifikasi atau modified starch, dengan sifat-sifat yang di kehendaki atau sesuai dengan kebutuhan (Wurzburg, 1989). Modifikasi pati secara kimia dilakukan melalui reaksi kimia sehingga gugus fungsional baru akan tersubtitusi pada molekul pati (Hermansson dan Svegmark, 1996 dalam Teja dkk, 2008). Gugus fungsional baru tersebut akan menggantikan gugus hidroksil $(-\mathrm{OH})$ pada molekul pati (Adebowale dan Lawal, 2002). Penerapan modifikasi pada pati akan meningkat karakteristik pati, seperti tekstur produk olahan pati yang lebih lembut, stabilitas tinggi, dan memiliki usia guna yang lebih lama dibandingkan dengan pati yang tidak termodifikasi (Yeh, 1993).

Penelitian modifikasi pati telah dilakukan oleh beberapa peneliti seperti Widiawan (2012), Herawati dkk (2009), Jasiah (2016) dan Damat dkk (2008). Beberapa faktor yang berpengaruh terhadap substitusi pati diantaranya adalah konsentrasi reaktan, dan jenis pati. Pada penelitian ini dikaji tentang hubungan antara konsentrasi anhidrida asam asetat terhadap kadar asetil dan derajat substitusi pati sukun asetat yang selanjutnya diaplikasikan pada pembuatan mie sebagai pengganti tepung terigu.

\section{METODE PENELITIAN}

\section{Bahan dan Peralatan}

Bahan yang digunakan dalam penelitian ini adalah buah sukun. Bahan kimia yang digunakan untuk sintesis pati sukun asetat antara lain anhidrida asam asetat untuk mensintesis pati sukun asetat, $\mathrm{NaOH} 3 \%$ sebagai pengatur $\mathrm{pH}, \mathrm{HCl} 0,5 \mathrm{~N}$ untuk mengasamkan, etanol $96 \%$ dan 
akuades digunakan untuk mencuci endapan. Bahan yang digunakan pada karakterisasi pati sukun asetat adalah $\mathrm{KOH}$ $0,5 \mathrm{~N}$ dan indikator PP.

Alat yang digunakan selama penelitian ini antara lain magnetik stirer, penangas air, botol semprot, neraca analitik, termometer, kertas saring, oven, statif, klem, desikator, hotplate, spektrofotometer FTIR dan alat gelas lainnya.

\section{Rancangan Penelitian}

Penelitian ini menggunakan Rancangan Acak Lengkap (RAL) dengan variabel bebas konsentrasi anhidrida asam asetatdengan variabel tetap persen asetil dan derajat substitusi. Variabel konsentrasi anhidrida asam asetatterdiri dari 5 taraf masing-masing dilakukan pengulangan sebanyak dua kali dengan jumlah unit percobaan sebanyak 10 unit.

\section{Prosedur Penelitian}

\section{Preparasi Sampel (Medikasari dkk, 2009)}

Buah sukun dikupas dan dibelah, selanjutnya dipisahkan daging buah dan dicuci hingga bersih. Kemudian daging buah sukun diparut dan ditambahkan air dengan perbandingan $5: 1$ ( 5 bagian air, 1 bagian buah). Campuran diaduk lalu disaring dengan kain saring selanjutnya didiamkan cairannya dalam baskom selama 24 jam. Lalu membuang airnya dan mengambil endapannya (pati). Endapan atau pati dikeringkan dalam oven suhu 70 oC selama 24 jam selanjutnya didinginkan.
Pati kering diblender kering dan diayak dengan ayakan 60 mesh untuk memperoleh tepung pati sukun yang halus.

\section{Sintesis Pati Sukun Asetat (Annison dkk, 2003)}

Tepung pati sukun sebanyak $100 \mathrm{~g}$ dilarutkan dengan $225 \mathrm{~mL}$ air suling dan diaduk selama 60 menit pada suhu $25^{\circ} \mathrm{C}$. Selanjutnya ke dalam suspensi tersebut ditambahkan larutan $\mathrm{NaOH} 3,0 \%$ sampai $\mathrm{pH}$ 10. Menambahkan $50 \mathrm{~mL}$ anhidrida asam asetat konsentrasi $0,05 \% ; 0,10 \%$; $0,15 \% ; 0,20 \%$ dan $0,25 \%$ dengan cara tetes demi tetes diaduk dan dibiarkan selama 20 menit. Kemudian suspensi diatur menjadi $\mathrm{pH} \quad 4,5$ dengan menggunakan larutan $\mathrm{HCl} 0,5 \mathrm{~N}$. Setelah terjadi endapan lalu disaring dan dilakukan pencucian dengan air suling hingga netral dan satu kali dengan etanol 95\%. Padatan kemudian dikeringkan dengan oven pada suhu $45^{\circ} \mathrm{C}$ selama 16 jam.

\section{Penentuan Kadar Asetil dan Derajat} Substitusi (Chen dan Voregen, 2004)

Pati sukun asetat ditimbang sebanyak $1,0 \mathrm{~g}$ dan dilarutkan dalam 50 $\mathrm{mL}$ etanol pada suhu $50^{\circ} \mathrm{C}$ selama 30 menit. Lalu didinginkan pada suhu ruang kemudian ditambahkan dengan $40 \mathrm{~mL}$ $\mathrm{KOH}$ 0,5 M dan disimpan selama 72 jam pada suhu ruang. Kelebihan alkali dititrasi dengan $\mathrm{HCl} \quad 0,5 \quad \mathrm{M}$ menggunakan fenolftalein sebagai indikator. Kadar asetil (\%) ditentukan sebagai berikut:

$$
\text { Kadar Asetil }(\%)=\frac{[(\mathrm{Vo}-\mathrm{Vn}) \times \mathrm{N} \times 43}{M} \times 100 \%
$$


Dimana :

Vo $=$ Volume $\mathrm{HCl}$ untuk titrasi blanko

$\mathrm{Vn}=$ Volume $\mathrm{HCl}$ untuk titrasi sampel

$\mathrm{N}=$ Normalitas $\mathrm{HCl}$

$\mathrm{M}$ = Berat sampel kering

43 = Berat molekul asetil $\left(\mathrm{CH}_{3} \mathrm{CO}\right)$

Derajat substitusi (DS) diihitung dengan persamaan sebagai berikut :

$$
\mathrm{DS}=\frac{(162 \times \text { kadar asetil })}{[4300-(42 \times \text { kadar asetil })]}
$$

Dimana :

162 = Berat molekul glukosa $\left(\mathrm{C}_{6} \mathrm{H}_{12} \mathrm{O}_{6}\right)$ $4300=$ Berat molekul asetil $\left(\mathrm{CH}_{3} \mathrm{CO}\right) \times 100$

42 = Selisih antara berat molekul gugus asetil dengan gugus - $\mathrm{OH}$

\section{Pengujian Organoleptik (Mendrofa, 2003) \\ Mie basah yang dihasilkan diuji} secara organoleptik (uji hedonik) oleh 30 panelis. Panelis menggunakan 5 skala untuk mengetahui tingkat kesukaan terhadap mie yang dihasilkan yaitu terhadap pati alami dan pati sukun asetat. Atribut mutu yang dinilai adalah rasa dan tekstur dengan masing-masing menggunakan 5 skala. Atribut mutu rasa digunakan skala 1-5 yaitu untuk skala $1=$ sangat tidak suka, 2 = tidak suka, 3 = agak suka, 4 = suka dan 5 = sangat suka sedangkan atribut mutu tekstur untuk skala 1 = sangat putus-putus, 2 = putus-putus, 3 = agak putus-putus, 4 = tidak putus-putus dan 5 = tidak putus-putus. Mie terbaik ditemukan berdasarkan uji pembobotan. Uji pembobotan dilakukan secara organoleptik menggunakan 30 panelis. Panelis memberikan bobot terhadap atribut mutu rasa dan tekstur. Mie yang mempunyai bobot paling tinggi dinyatakan sebagai produk terbaik.

\section{HASIL DAN PEMBAHASAN}

Pengaruh Konsentrasi Anhidrida Asam Asetat Terhadap Kadar Asetil

Modifikasi pati secara asetilasi bekerja dengan mensubtitusi gugus $-\mathrm{OH}$ (hidroksil) dengan gugus asetil, proses asetilasi terjadi pada kondisi alkali (basa). Uji kadar gugus asetil digunakan untuk mengevaluasi pati sukun hasil modifikasi dengan cara kimiawi. Salah satu faktor yang mempengaruhi kadar asetil pada modifikasi pati secara kimia adalah konsentrasi anhidrida asam asetat yang digunakan.

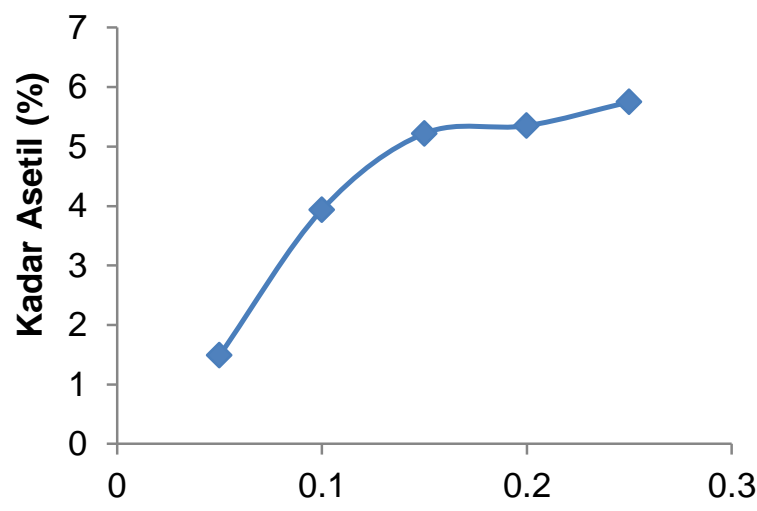

Konsentrasi Anhidrida Asam Asetat (\%)

Gambar 1 Nilai kadar asetil pada variasi konsentrasi anhidrida asam asetat

Hasil yang diperoleh terlihat pada Gambar 1 menunjukkan bahwa kadar asetil yang dihasilkan berkorelasi positif dengan meningkatnya konsentrasi anhidrida asam asetat. Kadar asetil tertinggi adalah 5,75\% diperoleh pada konsentrasi anhidrida asam asetat 0,25\%. Kadar asetil mengalami peningkatan, hal 
ini menunjukkan semakin tinggi konsentrasi, maka kadar asetil yang diperoleh akan semakin meningkat. Konsentrasi anhidrida asam asetat mempengaruhi kadar asetil yang dihasilkan.

\section{Pengaruh Konsentrasi Anhidrida Asam Asetat Terhadap Derajat Substitusi}

Derajat Substitusi atau DS menunjukkan berapa banyak jumlah gugus asetil yang dapat mensubsitusi gugus hidroksil $(-\mathrm{OH})$ pada pati. Hasil yang terlihat pada Gambar 2 menunjukkan peningkatan nilai Derajat Substitusi (DS) seiring meningkatnya konsentrasi anhidrida asam asetat. DS tertinggi diperoleh pada konsentrasi anhidrida asam asetat $0,25 \%$ yaitu sebesar 0,23 .

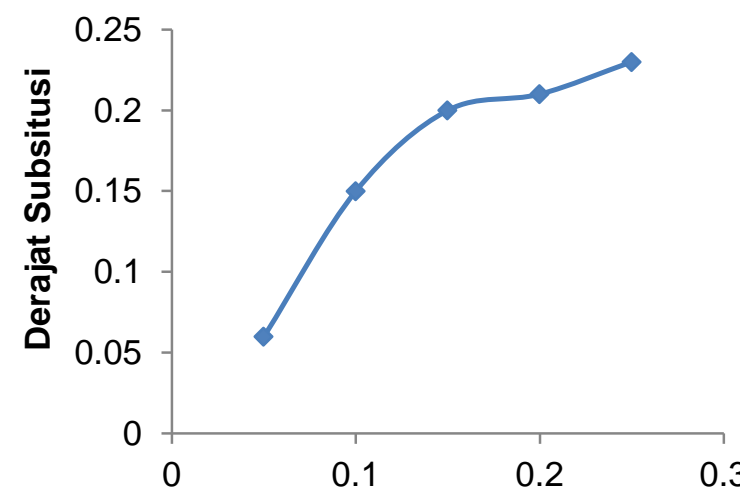

Konsentrasi Anhidrida Asam Asetat (\%)

Gambar 2 Nilai kadar asetil pada variasi konsentrasi anhidrida asam asetat

Hal ini terjadi karena semakin tinggi konsentrasi maka semakin banyak jumlah partikel sehingga akan menyebabkan gerakan molekul semakin cepat. Dengan demikian kontak antara pereaksi dan bahan semakin sering sehingga memberi kesempatan yang lebih besar untuk gugus asetil tersubstitusi pada gugus hidroksil. Faktor yang berpengaruh terhadap kecepatan reaksi yaitu konsentrasi reaktan, $\mathrm{pH}$, temperatur, lama reaksi dan jenis pati (Gonzales dkk., 200).

\section{Karakteristik Pati Sukun Asetat}

\section{a. Spektrum FTIR}

Identifikasi pengukuran gugus fungsional Pati Sukun Asetat dilakukan dengan menggunakan spektrofotometer infra merah (FTIR), dengan rentang panjang gelombang yang digunakan 4000$400 \mathrm{~cm}^{-1}$

Hasil spektrum FTIR pada pati sukun asetat menunjukkan puncak karakteristik pada $3377,36 \mathrm{~cm}^{-1}$ adalah kelompok hidroksil (-OH). Pada penelitian yang telah dilakukan oleh Muljana (2012), gugus $-\mathrm{OH}$ terletak pada bilangan gelombang $3416,5 \mathrm{~cm}^{-1}$ dan penelitian yang telah dilakukan oleh Rahim (2012), spektrum $-\mathrm{OH}$ terletak pada bilangan gelombang $3426 \mathrm{~cm}^{-1}$. Serapan pada bilangan gelombang 2927,94 $\mathrm{cm}^{-1}$ menunjukkan vibrasi ulur gugus $\mathrm{C}-\mathrm{H}$ alkana $\left(-\mathrm{CH}_{3}\right)$. Sesuai dengan hasil penelitian dari Rahim (2012), vibrasi ulur gugus $\mathrm{C}-\mathrm{H}$ alkana $\left(-\mathrm{CH}_{3}\right)$ terletak pada bilangan gelombang $2932 \mathrm{~cm}^{-1}$ dan penelitian yang telah dilakukan oleh Muljana (2012), spektrum gugus $\mathrm{C}-\mathrm{H}$ alkana $\left(-\mathrm{CH}_{3}\right)$ terletak pada bilangan gelombang 2998, $2 \mathrm{~cm}^{-1}$.

$$
\text { Penyerapan pada bilangan }
$$
gelombang 1645,28 $\mathrm{cm}^{-1}$ menunjukkan 
adanya gugus $\mathrm{C}=\mathrm{O}$ yang merupakan peregangan getaran dari kelompok ester. Menurut Sigit (2015), gugus $\mathrm{C}=\mathrm{O}$ terletak pada bilangan gelombang $1658,91 \mathrm{~cm}^{-1}$.
Pita serapan pada bilangan gelombang $1155,36 \mathrm{~cm}^{-1}$ menunjukkan adanya gugus fungsi C-O ester.

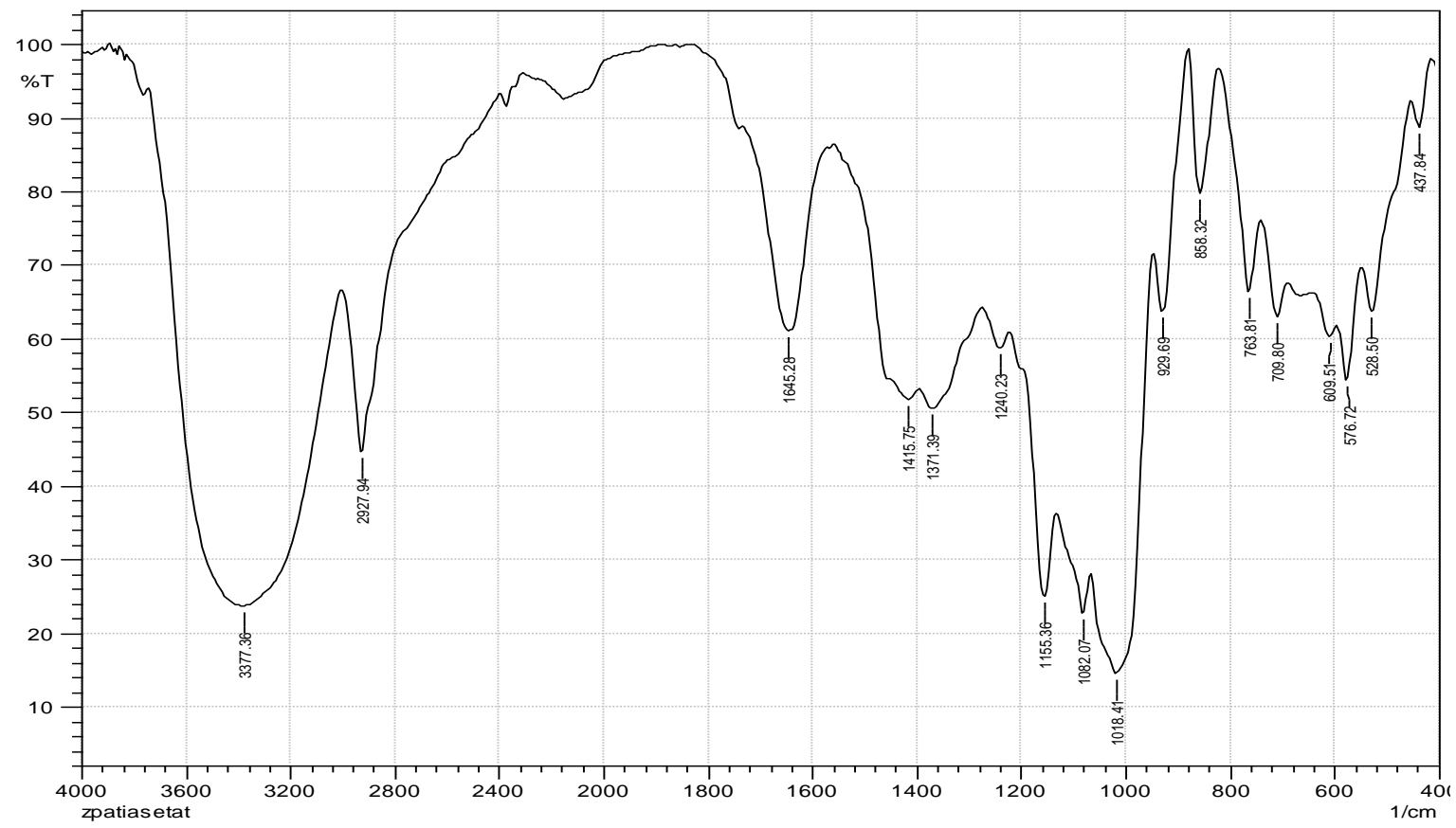

Gambar 3. Spektrum FTIR Pati Sukun Asetat

Menurut Muljana (2012), spektrum gugus fungsi $\mathrm{C}-\mathrm{O}$ ester terletak pada bilangan gelombang 1242,2 $\mathrm{cm}^{-1}$. Pada pita serapan pada bilangan gelombang $1018,41 \mathrm{~cm}^{-1}$ menunjukkan gugus fungsi CO glikosidik. Sesuai dengan laporan penelitian Muljana (2012), spektrum gugus fungsi C-O glikosidik terletak pada bilangan gelombang $1028,2 \mathrm{~cm}^{-1}$.

\section{b. Mutu Organoleptik Mie}

Uji organoleptik merupakan cara pengujian dengan menggunakan indera manusia sebagai alat utama untuk pengukuran daya penerimaan terhadap produk. Rasa merupakan faktor yang penting dalam menentukan keputusan bagi konsumen untuk menerima atau menolak suatu makanan.

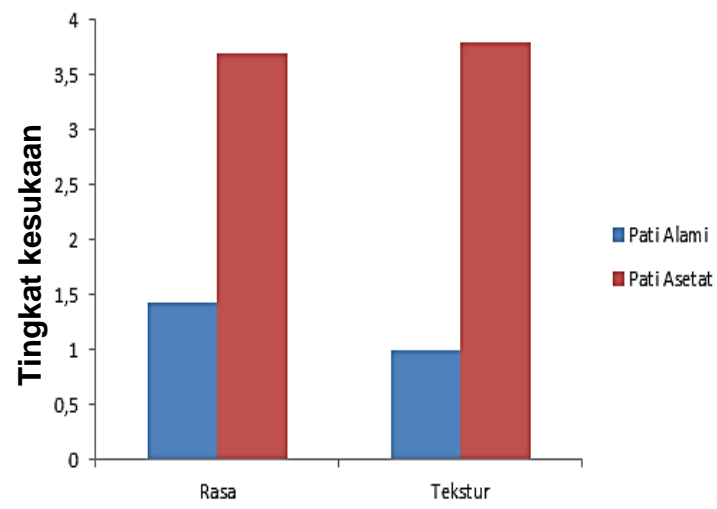

Gambar 4 Tingkat kesukaan kelompok/ Panelis terhadap parameter rasa dan tekstur

Dari hasil uji organoleptik dengan parameter rasa (Gambar 4), menunjukkan bahwa tingkat kesukaan kelompok 
(panelis) terhadap mie pati alami rata-rata 1,43. Hal ini berarti bahwa tingkat kesukaan kelompok (panelis) terhadap mie pati sukun alami dinilai cenderung tidak suka. Adapun tingkat kesukaan kelompok (panelis) terhadap mie pati sukun asetat rata-rata 3,7 . Hal ini berarti bahwa tingkat kesukaan kelompok (panelis) terhadap mie pati alami dinilai suka.

Dari hasil uji organoleptik pada parameter tekstur Gambar 4, menunjukkan bahwa tingkat kesukaan kelompok (panelis) terhadap tekstur mie pati alami rata-rata 1. Hal ini berarti bahwa tingkat kesukaan kelompok (panelis) terhadap tekstur pati alami dinilai sangat putusputus. Adapun tingkat kesukaan kelompok (panelis) terhadap tekstur mie pati asetat rata-rata 3,8. Hal ini berarti bahwa tingkat kesukaan kelompok (panelis) terhadap mie pati alami dinilai tidak putus-putus.

\section{KESIMPULAN}

Berdasarkan hasil penelitian dapat disimpulkan bahwa Konsentrasi anhidrida asam asetat yang terbaik didapatkan pada konsentrasi 0,25\% dengan kadar asetil $5,75 \%$ dan Derajat Substitusi (DS) 0,23. Hasil Uji organoleptik mie pati sukun asetat memiliki rasa dan tekstur yang lebih baik dibandingkan dengan mie pati alami

\section{DAFTAR PUSTAKA}

Adebowale, K. O., Afolabi, T. A., \& Lawal, O. S. (2002). Isolation, chemical modification and physicochemical characterisation of Bambarra groundnut (Voandzeia subterranean) starch and flour. Food chemistry, 78(3), 305-311.

Annison, G., Illman, R. J., \& Topping, D. L. (2003). Acetylated, propionylated or butyrylated starches raise large bowel short-chain fatty acids preferentially when fed to rats. The Journal of Nutrition, 133(11), 35233528.

Chen, Z., Schols, H. A., \& Voragen, A. G. (2004). Differently sized granules from acetylated potato and sweet potato starches differ in the acetyl substitution pattern of their amylose populations. Carbohydrate Polymers, 56(2), 219-226.

Damat, D., Haryadi, H., Marsono, Y., \& Cahyanto, M. N. Efek pH dan Konsentrasi Butirat Anhidrida selama Butirilisasi Pati Garut. Agritech, 28(2).

Gonzalez, Z., \& Perez, E. (2002). Effect of acetylation on some properties of rice starch. Starch-Stärke, 54(3-4), 148154.

Herawati, H., Widiasa, I N., Permanasari, D. (2009). Nilai Derajat Substitusi Pati Ester Dari Beberapa Metode Pengolahan. Seminar Rekyasa Kimia Dan Proses. Yogyakarta: Jurusan Teknik Kimia. Fakultas Teknik. Universitas Diponegoro.

Jasiah, I. (2016). Pengaruh Reaksi Esterifikasi Terhadap Kandungan Pati Resisten Tipe IV Pada Pati Sagu (Metroxylon. Sp). Skripsi. Program Studi Kimia Fakultas Sains Dan Teknologi UIN Sunan Kalijaga. Yogyakarta.

Medikasari, M., Nurdjanah, S., Yuliana, N., \& Lintang, N. (2012). Sifat Amilografi Pasta Pati Sukun Termodifikasi Menggunakan Sodium Tripolifosfat. Jurnal Teknologi \& Industri Hasil Pertanian, 14(2).

Muljana, H. (2012). Studi Proses Transesterifikasi Pati Sagu Didalam Media Subkritik $\mathrm{CO}_{2}$. Laporan 
Kegiatan Penelitian. Bandung: Jurusan Teknik Kimia. Fakultas Teknik Industri. Universitas Katolik Parahyangan.

Rahim, A., Haryadi., Cahyanto, M.N., Pranoto, Y. (2012). Characteristics of butyrylated arenga starch prepared at different reaction time and butyric anhydride concentration, International Food Research Journal, 19(4): 1655-1660.

Sigit, S. 2015. Asetilasi $\beta$-siklodekstrin Dengan Anhidrida Asam Asetat berkatalis $\mathrm{Fe}^{3+-}$ zeolit beta. Skripsi. Semarang: Jurusan Kimia. FMIPA. UNS.

Teja, A., Sindi, I., Ayucitra, Laurentia., Setiawan. (2008). Karakteristik Pati Sagu Dengan Metode Modifikasi Asetilasi dan Cross-Linking, Jurnal Teknik Kimia Indonesia, 7(3): 836843.

Triyani, A. P., Ishartani, D., \& Rahadian, D. A. (2013). Kajian Karakteristik Fisikokimia Tepung Labu Kuning (Cucurbita Moschata) Termodifikasi Dengan Variasi Lama Perendaman Dan Konsentrasi Asam Asetat. Jurnal Teknosains Pangan, 2(2). 29-38.

Widiawan, I., Nocianitri, K.A., Putra, N K. (2012). Karakterisasi Sifat FisikoKimia Pati Talas Kimpul (Xanthosoma Sagittfolium) Termodifikasi Dengan Metode Asetilasi. Laporan Kegiatan Penelitian. Bali: Jurusan IImu dan Teknologi Pangan Fakultas Teknologi Pertanian Universitas Udayana.

Wurzburg O. B. 1989. Modified starchs: properties and uses, Florida: CRC Press Inc.

Yeh, A. I., \& Yeh, S. L. (1993). Some characteristics of hydroxypropylated and cross-linked rice starch. Cereal Chemistry, 70, 596-596. 